\title{
'Grasping the Nettle'
}

\section{The report of the collegiate trainees' working party on consultant based services, $1985-1986^{*}$}

\section{Introduction}

The Collegiate Trainees' Committee, like the other bodies representing junior doctors, has been greatly concerned with the resolution of the present medical manpower problems of the NHS. Over the past few years a major and controversial aspect of the manpower debate has been the proposed change, throughout the National Health Service, towards a consultant based service. The committee has had difficulty in understanding what this change would mean for psychiatry in practice, and in September 1985 a working party was established with the following remit:

a) To discover what is meant by the term 'Consultant Based Psychiatric Services'.

b) To describe what models for such a service are currently in existence.

c) To describe the implications of the introduction of consultant based services in psychiatry for trainees, consultants and the College.

\section{Background}

The recent history of the concept of consultant based services starts with the 1981 report of the Parliamentary Social Services Committee ${ }^{1}$ the so-called Short Report. This report proposed that the number of consultants in the whole of the NHS be doubled by 1995, and that the number of trainees should be restricted to sufficient to fill projected consultant vacancies. It was anticipated that the consultant to junior ratio would increase to 1.8 to 1 with the consequence that many consultants in all specialities would find themselves working with minimal or no junior medical staff support. The consultant would thus be required to perform a greater amount of out-of-hours work and to have increased direct patient contact. The proposal was based on the belief that too much patient care was being carried out by medical staff in training and that if fully trained specialists were more involved in direct patient care there would be an improvement in both the quality and the efficiency of the service. A further benefit would be the resolution of the medical manpower problem.

The Short Report did not indicate how these changes might be organised clinically. Although the report's proposals were accepted by the Government more or less unequivocally ${ }^{2}$, no guidance was offered to Health Authorities as to how to bring about the necessary administrative and clinical changes. No extra funding was provided.

*This Report has been endorsed by the full committee of the CTC who wish it to be published as a discussion document; it is not (as yet) College policy.
The College has expressed various anxieties in response to the Short Report. ${ }^{3.4}$ The principal objections have been that the time scale is too short, that a crude doubling of consultant numbers would leave some sub-specialities still lagging behind present targets, that the clinical consequences are unknown and that the financial implications are greater than the Government has acknowledged. Furthermore, the College's policy on responsibilities within the multi-disciplinary team ${ }^{5}$ is that consultants cannot transfer responsibility to non-medical staff for legal, professional and ethical reasons. It is hard to imagine how a consultant based service could function without some traditionally medical activities being transferred to non-medical staff. This creates difficulties over consultant authority and responsibility which have not yet been fully addressed.

Psychiatry is in the process of re-organising itself to meet the demands of 'community care'. It is as yet unknown what overall effect this will have on the need for medical staff, and clearly this too affects the nature of any future consultant based service. The Collegiate Trainees' Committee has become increasingly frustrated at the inability of the College to help resolve any of these issues, resulting in a correspondence in the pages of the Bulletin between the previous Chairman of the CTC and the President of the College. ${ }^{6.7 .8}$

The professional bodies representing consultants have also been unable to look constructively at the realities of organising consultant based services. The Central Committee for Hospital Medical Services (CCHMS) of the BMA, whilst technically in favour of consultant expansion, has prevaricated over the Short Report. In October 1985 the committee 'offered clarification' of the various terms, and re-defined 'consultant based services' as a team, including junior doctors and led by a consultant. This is helpful as it appears to be a description of the present arrangement.

The Hospital Consultants and Specialists Association (HCSA) has led resistance to the Short Report with its alternative proposal for a 'specialist' grade, which is to say a tenured sub-consultant grade at senior registrar level. ${ }^{9}$ This working party believes that this proposal is redundant as it generates the same problems and objections as appointing large numbers of new consultants. There is no evidence that senior trainees would be willing to accept such posts, and fortunately the proposal has little support outside of the HCSA.

In 1985 the Parliamentary Social Services Committee reported $^{10}$ that minimal progress had been made in implementing its previous recommendations and urged the Government to take appropriate action. Following a somewhat diffident Government response, ${ }^{11}$ the Minister of 
State for Health, Mr Barney Heyhoe, established a Special Committee on Manpower with the Joint Consultants Committee (JCC) and the Department of Health and Social Security. This has recently reported ${ }^{12}$ and has introduced measures that are to be implemented from the 1 January 1987 , though inevitably delay has now occurred. The socalled Manpower Initiative is an attempt to resolve the manpower difficulties of the NHS by a combination of different approaches leading to a decrease in the number of trainees and an acceleration in consultant expansion. The concept of consultant based services is implicitly retained in the proposal that newly appointed consultants accept greater direct involvement in patient care. There is however a new proposal ('the safety net') to prevent junior staff support from falling below a locally agreed 'safe' minimum. This is to be achieved partially by the creation of an Intermediate Service grade at SHO/registrar level. The consequences of the Manpower Initiative for psychiatry are as yet unclear; the report repeatedly refers specifically to the acute specialities, and the 'pump priming' funds are to be directed to general medicine and general surgery. It seems that the objective of establishing consultant based services remains; however, this major report has, like its predecessors, failed to give guidance on clinical or administrative re-organisation.

\section{Experience of working without trainees}

In seeking examples or models for a consultant based psychiatric service, the working party has endeavoured to gather information from the widest possible range of sources. Firstly, a literature search was made for proposals for or descriptions of services operating within the United Kingdom without trainees. Only one such paper was found. ${ }^{13}$ Secondly, individuals were approached who were thought to have a particular interest or knowledge in the matter. Thirdly, enquiries were made to all psychiatric hospitals thought not to have approved training schemes, and which therefore might be supposed not to have psychiatric trainees. Finally, letters were published in the Bulletin and the Health and Social Services Journal requesting information from individuals with experience of, or plans for, running a psychiatric service in this way.

Although the working party received a large amount of correspondence as a consequence of these enquiries, much of it was speculative or sympathised with the difficulty in obtaining hard information. Only eight respondents were able to describe experience of working without junior medical staff, or to outline plans for future services. Opinion was sharply divided about the merits of working in this way. Even amongst those with first-hand experience, some were enthusiastic advocates, whilst others deplored the whole concept. Despite the differences of view point and setting, the services described were generally rather similar.

Initial assessment of patients is, in most present 'consultant based' services, carried out by the consultant. Much of the treatment of in-patients and out-patients is carried out by paramedical staff including community psychiatric nurses, psychiatric social workers, psychologists and physiotherapists as well as associate specialists and clinical assistants. There is an emphasis in several services on day patient treatment. Physical care of in-patients and out of hours medical emergencies on in-patient wards are covered by clinical assistant or hospital practitioner sessions. Day to day psychiatric management of in-patients is usually carried out partially by the consultant and partially by clinical assistants or associate specialists. Several respondents emphasised the importance of maintaining close working relationships with general practitioners and there was a general suggestion that some of the workload had to be referred out to other agencies, such as social services. The function of the consultant seems to be principally as supervisor and co-ordinator of a largely non-medical multi-disciplinary team, with direct patient contact being concentrated at the assessment stage; several respondents indicated the need for special skills in working in multidisciplinary teams. Various methods of covering administrative duties were described, such as having a fixed tenure medical director with limited clinical involvement. There was a general emphasis on having adequate numbers of consultants, particularly to allow study and annual leave. To summarise the advantages and disadvantages of this kind of service identified by our respondents:

\section{Advantages}

1. Early assessment by a consultant reduces the number of in-patient admissions.

2. Well trained permanent non-medical staff are usually clinically more useful than psychiatric trainees.

3. Patients benefit from increased consultant contact and this also improves consultant job satisfaction.

4. Repeated changes of junior doctor are avoided and this improves continuity of care.

5. Clinical decisions are made faster and tend to be of a better quality.

\section{Disadvantages}

1. Working in this way is hard work for the consultant, with a heavy out-of-hours commitment.

2. The use of non-psychiatric medical staff for physical care can lead to a undesirable split between care of mind and care of body.

3. Difficulties can arise regarding the level of clinical autonomy of permanent non-consultant staff.

4. Study leave, holidays, and administrative duties can be difficult to organise.

5. Consultants are not exposed to new ideas nor are they challenged and this can lead to stagnation.

6. Clinical experience is diluted by an excess of routine work and consultants may become less able to cope with unusual or difficult clinical problems; this can lead to an increase in tertiary referrals.

7. Once junior staff have been withdrawn, it is difficult to regain funding and training approval, and thus the step seems irreversible.

8. The service is highly dependent on the quality of its paramedical staff. In view of the current difficulties in 
psychiatric nurse recruitment and the consequent low level of staffing, this is in doubt.

9. Senior Registrars are not trained in running such a service and are reluctant to take up this kind of post. It is feared that this will lead to a 'polarisation of talent' between the periphery and the teaching centres.

10. Trainees need experience of working in peripheral hospitals: if consultants are working without trainees it follows that this experience is lost to trainees.

11. Health Authorities are prone to regard consultant based services as a cheap option, but this is not the case and they may be more expensive than existing services.

Conclusion

To return to the working party's remit:

a) The term 'Consultant Based Pychiatric Service' means a service where the consultant has little or no support from psychiatric trainees. This does not imply that the consultant works single handedly and indeed increased support from non-medical staff seems to be an essential feature.

b) There is only very limited experience in this country working outside of the traditional hierarchical model of medical staffing. There is a pressing need for systematic research into various alternative ways of organising clinical psychiatric services. To either hope that change will never come or to press ahead without assessing the effects upon the service offered to patients can only be regarded as foolhardy.

c) In the wake of the JCC/DHSS Manpower Initiative it is likely that change will occur more rapidly than in recent years. Certain issues must be resolved, namely:

1. The College will have to reconsider its policy on the nature of consultant responsibility and accountability and the relationship between the two. This issue may need the attention of the GMC and Parliament. Other professions, especially nursing, will have to meet the challenge of an altered role and increased personal responsibility.

2. The College will have to alter its training requirements to ensure exposure to this type of service in Senior Registrar training schemes.

3. There will have to be an alteration in the numbers of Senior Registrars both in total and across subspecialities and this will require central manpower planning. The current deliberations of JPAC may have to be reviewed.

4. A large proportion of consultants must be prepared to face the daunting challenge of making an irreversible step towards new working practices and workloads. Trainees will have to adjust their expectations of their eventual consultant post.

5. Steps will have to be taken to avoid the excessive concentration of trainees in teaching centres with a resultant polarisation between peripheral hospitals and teaching centres.
6. There are important financial implications regarding both the level of remuneration to paramedical staff to ensure a continued supply of good quality staff, and to compensate consultants for increased workload. The Government must be prepared to provide continuing funding over and above the 'once off' cash of the Manpower Initiative, to fund both the new style services and research into the organisation of services.

7. Provision of physical care to in-patients on a sessional basis (eg by clinical assistants) is unsatisfactory, and whilst it is not easy to envisage an alternative, this arrangement cannot become part of a model for organising psychiatric services nationally.

The Working Party believes that consultant based psychiatric services as stated above represent one viable pattern of psychiatric practice, despite some major unresolved difficulties associated with it. We emphasise the need for systematic research on the issue, and remain sceptical of the ability of the various parties, not least the College, to grasp the nettle (6) and to cope with the challenge involved.

R. G. POOLE Convenor

\section{ACKNOWLEDGEMENTS}

The Working Party would like to thank all those who provided information, and in particular $\mathrm{Dr}$ Alasdair McDonald, and Drs D. G. Kingdon and T. K. Szulecka, who gave us details from their own papers which have been submitted separately for publication.

\section{REFERENCES}

${ }^{1}$ DHSS (1981) Fourth Report from the Social Services Committee, 1980-1981 Session. London: HMSO.

${ }^{2}$ DHSS (1982) Government Response to the Fourth Report from the Social Services Committee. London: HMSO.

${ }^{3}$ Caldicotr, F. (1982) 'The Short Report and its implications'. Bulletin of the Royal College of Psychiatrists, 6, 155-157.

${ }^{4}$ RAWNSLEY, K. (1984) The future of the consultant in psychiatry: A report to the College. Bulletin of the Royal College of Psychiatrists, 8, 122-123.

${ }^{5}$ Royal College of Psychiatrists (1984) The responsibilities of consultants in psychiatry within the National Health Service. Bulletin of the Royal College of Psychiatrists, 8, 123-126.

${ }^{6}$ Hollyman, J. A. (1985) An open letter to the President from the Collegiate Trainees' Committee. The Bulletin of The Royal College of Psychiatrists, 9, 34.

'BewLeY, T. (1985) A reply to Collegiate Trainees' Committee open letter. Bulletin of The Royal College of Psychiatrists, 9, 118.

${ }^{8}$ Hollyman, J. A. (1985) Career structure and recruitment in psychiatry. Bulletin of the Royal College of Psychiatrists, 9, 249.

${ }^{9}$ Hospital Consultants and Speciallsts Association (1981) The future pattern of hospital staffing, The Consultant, February, 12-14.

${ }^{10}$ DHSS (1985) Fifth Report from the Social Services Committee. 1984-85 Session. London: HMSO.

${ }^{1}$ DHSS (1986) Government Response to the Fifth Report from the Social Services Committee. London: HMSO.

${ }^{12}$ DHSS/JCC (1986) Hospital medical staffing: achieving a balance. British Medical Journal, 293, 147-151.

${ }^{13}$ KINGDON, D. G. \& SzULECKA, T. K. (1986) Establishing a district psychiatric service without psychiatric trainees. Bulletin of the Royal College of Psychiatrists, 10, 338-340. 